\title{
MOUTH, FAUCES, Etc.
}

Barstow, D. M.-A Contribution to the Study of Peritonsillar Abscess "Med. Record," April 19, 1902.

According to the author the fons et origo of peritonsillar abscess appears to lie in the supratonsillar recess, and not, strictly speaking, in the tonsil itself.

The plan of treatment advocated is to open up the supratonsillar recess so freely that it will effectively drain, and to repair its diseased mucous membrane. To effect this, cocaine solution is injected into the body of the tonsil and into the peritonsillar regions. With a bistoury an incision is made from above downwards, dividing the plica triangularis at its base from the anterior pillar. With a. Myles' tonsil punch the entire upper part of the tonsil is removed piecemeal, together with a part or the whole of the plica triangularis. ficial.

The effect of this operation is, according to the author, very bene-

Brown, E. R. (Montreal).-Unusual Tumour of Soft Palate. "Montreal Medical Journal," December, 1891.

The patient was a male, aged forty-five years, with a strong antivenereal history, but with a marked tendency to the development of gout. He had suffered several times from attacks of pain and swelling of the metatarso-phalangeal joint of the great toe, and as often from swelling and pain in the soft palate; the two never occurred at the same time.

Examination revealed a tender mass of a vivid pink colour, situated in the right half of the soft palate, simulating a gumma. The interest was in the diagnosis. Owing to the history of the case, the tumour was considered to be probably of a gouty character. It was treated as such, with rapid and complete disappearance of all symptoms.

\section{Price-Broun.}

Clauda.--A Case of Perforating Tuberculous Ulceration of the Soft Palate. "Arch. Internat. de Laryngologie," etc., January, 1902.

These cases are rare. Dr. Clauda only knows of nine othersthree reported by Dr. Castex, three by M. Dieulafoy, one by M. Talamon, one by M. Ducastel, and one by M. Barbier. Diagnosis is not difficult, as evidence of tuberculous disease is found in the lungs or larynx; difficulty in swallowing is much more marked than in syphilitic ulceration of the palate.

Applications of lactic acid-varying in strength from 1 in 10 to 1 in 3 -were used, with satisfactory results, so far as the local ulceration was concerned, but the patient ultimately died from extensive lung mischief.

Anthony McCall.

Descos.-Angina due to Friedländer's Pneumo-bacillus. "Isa Presse Méd.," March 5, 1902.

Cases of angina due to the pneumo-bacillus are rare. Nicolle and Hébert, in their review of the subject, published in 1899, could find only nineteen cases. Since that date three cases have been reported, to 
which the author now adds a fourth. His case was that of a man, aged thirty-eight, who came into hospital for advanced pulmonary tuberculosis. A few days after admission he complained of slight dysphagia. Examination of the throat revealed several small, gray, slightly-raised spots on the left anterior pillar and left half of the soft palate. The spots spread slowly, and united so as to form false membranes covering the left tonsil, left anterior pillar, soft palate, and uvula, then the right anterior pillar and right tonsil, finally involving the whole faucial isthmus and posterior parts of the gums. In spite of its wide distribution the lesion gave rise practically to no pain, and the interference with deglutition was purely mechanical. It was impossible to say what influence the throat lesion had on the pulmonary condition, or vice versâ. The patient died of pulmonary tuberculosis at the end of two months.

The membranes were extremely tenacious; only the superficial parts could be removed with a swab: to remove the deeper parts a curette had to be used; the subjacent mucosa was then left swollen and bleeding. These membranes were submitted to bacteriological examination. The deep layers were found swarming with Friedländer's pneumobacillus, whilst the superficial layers were poor in microbes, but contained besides the pneumo-bacilli also a few cocci and some filaments and spirilla; but there was no diphtheria bacillus or tubercle bacillus in any of the specimens.

The author gives a detailed account of the culture experiments to which the bacilli were submitted. Arthur J. Hutchison.

\section{NOSE AND NASO-PHARYNX.}

Clark, J. Payson (Boston). - Report of Two Cases operated on for Deformity of the Nose. "Boston Medical and Surgical Journal," March 6, 1902.

In the first case the deformity might have been termed an exaggerated snub-nose, due to an overgrowth forward of the triangular cartilage of the septum, drawing up the tip of the nose and giving it an irregular, knob-like appearance. Through an incision in the inucous membrane of the left nostril, the skin was freed from the prominent portion of the nose, and the required amount of the redundant cartilage removed with a pair of curved scissors, and the nose dressed with a gauze plug and pad to keep it in position.

The second case was due to two falls on the nose, driving it laterally to the left, with considerable thickening of the right nasal bone. The blade of a narrow-bladed pair of scissors was pushed through the cartilaginous septum to its anterior border, $2 \frac{1}{2}$ centimetres from the tip of the nose, and the cartilaginous and osseous septum divided, keeping to the line of the deformity. The nasal bones were sawn away from their articulation with the upper maxilla and broken away from their attachment to the frontal bone. After the operation the nose was kept in the desired position by means of strapping and pads of gauze.

Both operations were successful.

StGeorge Reid.

Collet, F. J.-Vertigo of Nasal Origin. "Annales des Maladies de l'Oreille, du Larynx," etc., February, 1902.

Dr. Collet reports a case as follows: "The patient, a young man (thirty-two), complained of a tickling in his nose and a violent attack 